\title{
STUDENT GUIDANCE DECISIONS AT TEAM MEETINGS: DO TEACHERS USE DATA FOR RATIONAL DECISION MAKING?
}

\author{
ROOS VAN GASSE, \\ MARTINE MOL
}

\begin{abstract}
In the past decade, the belief has grown that student guidance decisions can benefit from systematic data use. Systematic data use can be considered as completing the circle of inquiry (from data discussion to interpretation, to analysis, diagnosis, and action) with a reasonable depth. However, little is known about how teachers use data to inform student guidance decisions. This qualitative study analyzed the field notes of 17 teachers' meetings that were intended to formulate student guidance decisions in secondary education. The results showed that data were used only sporadically and often not in a systematic way. Moreover, the depth of inquiry in formulating diagnoses on poor student functioning was low. These results indicate a need to raise awareness among teachers and policymakers on the stepwise and self-questioning process that data use should be in order to be effective.
\end{abstract}

Keywords

student guidance, data use, teacher meetings, secondary education 


\section{Introduction}

Teachers make decisions every day, often related to student guidance. "What can I do to improve this student's learning process?" is a question all teachers are familiar with. How teachers deal with this question is vital for student learning, but also for their learning trajectories and for what education can bring about for them.

This idea and the quest to close the gap for disadvantaged students in education initiated the conviction that teacher decisions on student guidance can benefit from an adequate use of data (i.e., all the information that can inform teachers about student functioning) (Wayman et al., 2013). Data use is a systematic process with a sequence of subphases around the discussion and interpretation of data, the definition and analysis of potential causes (i.e., diagnosing phase), and the formulation of improvement actions (Schildkamp et al., 2016; Van Gasse et al., 2017). The systematic use of data such as test scores or classroom observations is considered a means of preventing teachers from hasty decisions on pupil guidance because such use challenges cognitive biases and preconceptions. That the systematic use of data has the power to prevent teachers from such biases has been supported by empirical evidence. In the past decade, research has shown that adequately using data can result in better instructional decisions and eventually in increased student achievement (Campbell \& Levin, 2008; Carlson et al., 2011).

Two aspects are vital to effective data use. The first aspect relates to the sequential activities needed to arrive at an inquiry cycle that challenges existing assumptions. The literature has distinguished phases of (1) data discussion and interpretation in which data is contextualized and transformed into information, (2) diagnosis ofpotential causes in which hypotheses are challenged and investigated, and (3) formulating improvement actions in which appropriate actions for the defined problems are designed. Research has shown that such inquiry cycles interrupt the human tendency to jump to conclusions without identifying causes based on data (Schildkamp et al., 2016). The phases provide guidance for teachers to thoughtfully investigate and reflect on classroom and school practices. Therefore, data use processes that have gone through the inquiry cycle can result in concrete improvements, such as improvements in the classroom (Van Gasse et al., 2017). However, the literature on data use reveals that teachers generally do not have the capability to systematically collect and use data appropriately (Datnow \& Hubbard, 2016). Teachers experience problems with interpreting data or investigating potential causes, or with determining which improvement actions are appropriate within a certain situation (Bertrand \& Marsh, 2015). As such, the data use cycle is often hampered and the full potential of data use cannot be reached. 
Following the inquiry cycle for data use does not in itself ensure improvements based on data. Even if these sequences are correctly followed, great differences remain regarding the depth of investigation that is achieved across different teacher teams (Schildkamp et al., 2016). The reflective stance that teachers take in creating knowledge based on data can in turn produce a range of different knowledge outcomes and is thus critical in this regard (Hubers et al., 2016). Data users who do not question their own role in defining problems or causes will not reach the depth of investigation needed to achieve far-reaching improvements through data use. Therefore, the depth of inquiry is the second aspect that is crucial to effective data use (Schildkamp et al., 2016).

However, although knowledge is available on what effective data use practices look like, there is limited evidence on how teachers systematically use data to discuss student progress and achievement at formal team meetings and on whether data use reaches its full potential in this context. Generally, the literature outlines a rather pessimistic situation in data use (Van Gasse et al., 2017). How teachers use data for guiding students successfully through their trajectories has not yet been extensively investigated. Moreover, in-depth knowledge on how the decision processes in team meetings on this topic involve appropriate data use remains underexplored. The sequence of the data use cycle and the depth of investigation in data use practices are key. Nevertheless, integrating these perspectives for an in-depth examination of data use practices has been done in only one intervention-based study that was not specifically related to guiding student trajectories (i.e., Schildkamp et al., 2016). Therefore, when considering what effective decisions on student trajectories can produce in terms of what education can bring about for students, knowledge is needed on how teachers use data in formative team meetings on student progress and more specifically on how they run through the data use cycle and to which degree of examination depth. The following research questions guide this study:

1. To what extent do formal teacher teams incorporate the data use cycle?

2. What is the depth of inquiry of data use processes in formal teacher teams?

\section{Context of this study}

Educational decisions in this study are situated in the context of formal student guidance meetings in Flemish secondary schools (12- to 18-year-old students). These class-group level team meetings take place two or three times a year (i.e., once in September, once in December, and in lower grades once in April). In the first meeting at the beginning of the school year, teachers discuss the student dossiers. The second meeting (i.e., the one that was 
observed for this study) is for discussing student progress during the year. This meeting informs the team meeting at the end of the school year that serves to advise student trajectories. The teams under study are temporary and interdisciplinary (Vangrieken et al., 2013), and are collectively responsible for the learning of a group of students. In the guidance meetings, the teams discuss the student learning progress and functioning to improve student guidance. The meetings involve all teachers who teach a certain subject in the student group, supplemented by a student counsellor.

The study took place in Flanders. Flemish schools have a lot of freedom to design student guidance and the Flemish government does not collect specific data to support this (e.g., learning monitoring systems or central tests). Schools themselves are responsible for insight into whether they reach the Flemish standards at the end of secondary education (De Volder, 2012). Thus, governmental expectations toward data use are rather implicit and the responsibility for using data and support for data use lie with individual schools and teachers. Therefore, data is broadly conceptualized and includes all data related to student functioning. This data can be both qualitative (i.e., observations) and quantitative (i.e., class tests).

\section{Theoretical Framework}

\section{Data use and data}

Data use is not simply about data. It refers to a sequence of activities in which data are transformed into knowledge for making rational decisions (Coburn \& Turner, 2011; Marsh, 2012). Therefore, data use is a less straightforward activity than it seems. It is a complex inquiry process in which current situations are fully analyzed and improved.

Effective data use is a reflective process that follows a certain sequence (Ciampa \& Gallagher, 2016; Marsh \& Farrell, 2015). This sequential process supports teachers in the translation from data into meaningful decisions (Marsh et al., 2015). The tendency to jump from data to improvement actions without in-depth consideration of potential causes and alternatives is interrupted by explicitly installing the different inquiry phases in data use (Hubers et al., 2017; Schildkamp et al., 2016). Therefore, the presence or absence of the phases is an indicator of the quality of the data use process and is essential to expand and refine the knowledge as to how teachers use data to decide on student guidance decisions.

The first step in the data use sequence is to define the educational problem. In this phase, teachers formulate the problem independent of data. Data use generally does not start with data, but with problems teachers encounter (Schildkamp et al., 2016). After collecting (or selecting) data, the subsequent 
phase of the data use cycle is discussing and interpreting data in relation to the educational problem. Interpreting data correctly transforms data (which are independently meaningless) into information. In the third step, the problem diagnosis, a deliberation of potential causes and explanations is carried out. This implies that knowledge is created based on the available information. The final phase involves the formulation of educational decisions (e.g., designing improvement actions that can be implemented in the classroom) (Verhaeghe et al., 2010).

The data use cycle may seem linear and straightforward. However, the literature has shown that data use cycles are often interrupted or that teachers return to previous phases (Marsh \& Farrell, 2015; Schildkamp et al., 2016). Non-linear sequences in data use are generally not seen as problematic and are part of the inquiry process. Nevertheless, completing the full cycle has proven essential for solving the presented educational problems (Gelderblom et al., 2016). Despite this knowledge, apart from intervention studies very limited evidence is available on teachers going through the data use cycle at formal meetings.

\section{Depth of analysis}

Completing the full data use cycle is essential for the quality of data use in schools. However, running through all the phases of this sequence does not automatically imply data use trajectories of high quality. Also between similar teacher teams that follow the circle of inquiry, large differences occur in the quality of the inquiry processes and the associated results (Hubers et al., 2016; Schildkamp et al., 2016). Schildkamp et al. (2016) found differences between teams regarding the depth of inquiry throughout the circle of inquiry. And the research by Hubers et al. (2016) showed that identical sequences in data use can result in different knowledge creation in teams. Thus, the success of data use strongly depends on what happens during the different phases of the circle of inquiry.

Differences in how teams evolve during the data use cycle can be explained by user characteristics (e.g., self-efficacy, attitude), school characteristics (e.g., school culture), and context characteristics (e.g., accountability context) (Datnow \& Hubbard, 2016; Ehren \& Swanborn, 2012; Van Gasse et al., 2017). However, even between similar teams, schools, and (data use) contexts, large diversity in data use processes can occur (Schildkamp et al., 2016). Research has shown that the effectiveness of data use processes depends on the way in which new knowledge is created, or in the diagnosing phase. In this phase, it is necessary to combine different types of knowledge to define causes for the presented educational problem (Gummer \& Mandinach, 2015). Therefore, this phase is crucial for the quality of data use and introduces great differentiation between data users. 
Attribution and diagnosis

Research has shown that teachers generally formulate external causes for educational problems (e.g., problems related to student capacity or student home environment) (Schildkamp et al., 2016). It is usually only when these formulated causes turn out to be incorrect that teachers start searching for explanations that are related to the school or their own functioning and become able to solve the presented educational problem (Schildkamp et al., 2016). Therefore, the attribution of causes in the diagnosing phase can be considered as a potential indicator for the depth of the inquiry process in data use. Nevertheless, insights into this attribution of causes in data use processes are rather limited.

According to Weiner (2010), attribution theory states that formulated causes have a multidimensional character. The first is the causal locus. Causes can be attributed to internal factors (e.g., high competency can lead to success on a test) or external factors (e.g., success on a test can depend on its difficulty). The second dimension is the causal stability. Whereas one's competences can be considered a stable cause, the effort one invested in a task can be seen as unstable. The third dimension Weiner (2010) distinguished is causal control. Task difficulty cannot always be controlled; effort is controllable. Thus, formulated causes can be placed in a multidimensional space of causal locus, causal stability, and causal control.

The work of Schildkamp et al. (2016) is one of the first studies that used the idea of causal attribution to investigate the depth of inquiry in data use processes. In this regard, the study mainly focused on the causal locus in the diagnosing phase in data use in the sense that internal causes (e.g., teacher behavior) were distinguished from external causes (e.g., student prior knowledge level). In this study, we also examine the causal control that teachers perceive. Schildkamp et al. (2016) already noted that even when causes are externally attributed (e.g., student motivation), it is important that teachers reflect on their role in exercising control over it (e.g., how can I motivate my students?). Therefore, the perceived causal control not only comes to the surface in the discussion on causes (i.e., diagnosis), but also in the decisions on follow-up actions (i.e., action phase).

Attribution and formulating actions

Follow-up actions in data use can take different forms. Coburn and Turner (2011) distinguished four types of possible actions when it comes to data use to improve classroom practices. First, teachers may choose to adapt their instruction for (some) students. This implies that they change their behavior. However, this type of educational improvement is not self-evident. Research has provided some indications of changed teacher behavior (Ebbeler et al., 2017), but this appears to be less common in research out of the scope of 
intervention settings (Van Gasse et al., 2016). A second possible action is to provide students with supplemental materials on certain topics (Coburn \& Turner, 2011). Examples can be additional or different exercises or supportive materials for certain lessons. Grouping students is a third strategy. When data show, for example, that some students need extra attention on some topics, teachers may choose to split the student group in smaller groups that go through the subject matter at their own manner or pace. The last action Coburn and Turner (2011) distinguished are actions on other dimensions of the classroom and school practices. Examples may include that the school is organized differently (e.g., more individualization of learning trajectories) as a result of data use practices.

Following attribution theory, it is likely that the concrete actions that are formulated after a data use sequence are related to the causal locus and the causal control that are perceived by teachers. It is, for example, less likely that teachers will change their instruction when they perceive that poor student results are due to the fact that the student chose a wrong educational track for their cognitive capacities (i.e., external locus - no perceived control) (Schildkamp et al., 2016). When teachers are convinced that they can exercise control over the situation, other actions may be formulated (Schildkamp et al., 2016). For example, when teachers are convinced that a student's poor results are due to a lack of motivation (external locus), and they are convinced that they can affect this motivation (causal control), a potential data use outcome may be that teachers agree on making changes in their instruction to motivate students (Baten et al., 2020). However, when teachers consider their students' motivation as an uncontrollable factor, this type of action will not be formulated (Weiner, 2010). Therefore, the depth of inquiry through causal attribution comes to surface in the perceived causes and it is also reflected in the actions that are formulated.

\section{Method}

\section{Participants, design, and instrument}

This qualitative study used observations to examine data use in formal team meetings in Flemish secondary schools. Data were collected within two secondary schools (ISCED 2 and 3) in Flanders. The two schools participated voluntarily. Within the schools, all team meetings were observed that (1) took place on two meeting days, (2) did not show overlap with other meetings in the meeting schedule, and (3) included teachers providing consent to the observation. In total, 17 team meetings of 17 classes were observed. The number of students in each class ranged between 3 and 18 with a median of 8 . Across the team meetings, we collected data for 149 student guidance processes. 
The teams were responsible for the learning of students (14- to 18-year-old students) in technical and vocational tracks. The team meetings took place among all teachers of the class (generally about 11, teaching different subjects to the class) and the student counsel. The meetings served in discussing the progress of students during the school year and for making appointments on student guidance decisions. In the sample schools, three minutes of discussion per student was scheduled. Both achievement and social-emotional behavior are possible subjects for discussion.

For the observations, the two researchers collaboratively developed an observation sheet based on the theory of data use. In this sheet, the different phases of the circle of inquiry were included: discussion and interpretation, diagnosis, and action. The observation process was twofold. For every student out of the student group was an indication of whether the different phases in the sequence were followed (by adding a 1 or a 0 ). Open observational notes were added, including which data were analyzed, what causes were formulated, etc. In this way, the observations combined a quantitative and qualitative observation approach. All 17 formal team meetings were observed systematically following this observation scheme by one independent researcher (the second author).

\section{Analyses}

\section{The extent to which formal teams incorporate the data use cycle}

To answer the first research question, the binary data of the observation sheets were analyzed. In a first step, the total number of students for whom data-based discussion and interpretation, diagnosis, and action took place at the formal team meetings was calculated per team meeting. Subsequently, the ratio of this number and the total student population that was subject of the team meeting was calculated. This resulted in an occurrence ratio of data discussion and interpretation, diagnosis, and action for each team meeting. As such, we investigated the extent to which formal teams incorporated the data use circle of inquiry in student guidance discussions.

Additionally, our analyses of the data use cycle took an in-depth approach. Based on the binary data of the coding scheme, we examined the extent to which the formal teams completed the data use sequence (i.e., formulating actions after discussion and interpretation and diagnosis). To this end, we counted the "complete" processes per team meeting. Subsequently, we investigated why some data use cycles were incomplete. We looked at the number of sequences that stopped or were not implemented as prescribed by theory (e.g., skipping the diagnosing phase). 


\section{The depth of inquiry in data use}

To analyze the depth of inquiry, we analyzed the researcher's open observation notes in the observation schemes. In line with the theoretical framework, we focused on the diagnosis and action phases for this analysis. First, we coded the causes that were discussed in the formal team meetings and the actions that were decided on in different axial codes that were discussed by the two researchers. These codes were then clustered into the presented theoretical framework (see Table 1).

Table 1

Coding tree

\begin{tabular}{|c|c|c|}
\hline & Cluster & Axial codes \\
\hline \multirow{4}{*}{$\begin{array}{l}\text { Diagnosing } \\
\text { phase }\end{array}$} & Internal locus - uncontrollable & - \\
\hline & External locus - uncontrollable & $\begin{array}{l}\text { Learning disorder } \\
\text { Problematic home situation } \\
\text { Medical problem }\end{array}$ \\
\hline & External locus - controllable & $\begin{array}{l}\text { Subject-specific learning problem } \\
\text { Learning attitude problem } \\
\text { Language problem } \\
\text { Emotional problem }\end{array}$ \\
\hline & Internal locus - controllable & - \\
\hline \multirow[t]{4}{*}{ Action phase } & Adapting instruction & $\begin{array}{l}\text { Adapted student guidance in class } \\
\text { Adapted learning trajectory } \\
\text { Catch-up lessons }\end{array}$ \\
\hline & Materials & $\begin{array}{l}\text { Remedial assignment } \\
\text { Holiday assignment } \\
\text { Extra test } \\
\text { Extra exercises }\end{array}$ \\
\hline & Grouping pupils & - \\
\hline & Other dimensions & $\begin{array}{l}\text { Follow-up meetings (parents / students) } \\
\text { Behavioral contract }\end{array}$ \\
\hline
\end{tabular}

In a next step, the axial codes were clustered. For the diagnosing phase, the clustering was based on the theory of causal attribution. Each axial code was assessed on the dimensions causal locus and causal control. For the action phase, the clustering was based on the different actions that were distinguished by Coburn and Turner (2011): adapting instruction, adapting materials, grouping pupils, and other dimensions of the classroom and school practice.

This coding process resulted in an in-depth cross-case analysis of the diagnosing and action phases of the different formal teams. 


\section{Results}

The data use cycle in teacher teams

Table 2 shows the extent to which the different phases in problem diagnosis were carried out within the different team meetings. The table provides the raw number of pupils for whom data were discussed and interpreted, for whom data were searched for causes (diagnosis), and for whom actions were formulated. The ratio of students subject to a certain phase of data use and the total number of students are expressed in percentages.

Table 2

Data use at formal student guidance meetings

\begin{tabular}{|l|c|c|c|c|}
\hline Team & $\begin{array}{c}\text { N students in } \\
\text { class? }\end{array}$ & $\begin{array}{c}\text { Discussion and } \\
\text { interpretation }(\%)\end{array}$ & Diagnosis (\%) & Action (\%) \\
\hline $\mathbf{1}$ & 8 & $3(37.5)$ & $0(0)$ & $1(12.5)$ \\
\hline $\mathbf{2}$ & 9 & $5(55.6)$ & $5(55.6)$ & $5(55.6)$ \\
\hline $\mathbf{3}$ & 10 & $2(20.0)$ & $1(10.0)$ & $1(10.0)$ \\
\hline $\mathbf{4}$ & 5 & $2(40.0)$ & $1(20.0)$ & $2(40.0)$ \\
\hline $\mathbf{5}$ & 8 & $7(87.5)$ & $5(62.5)$ & $4(50.0)$ \\
\hline $\mathbf{6}$ & 8 & $1(12.5)$ & $1(12.5)$ & $1(12.5)$ \\
\hline $\mathbf{7}$ & 6 & $4(66.7)$ & $4(66.7)$ & $1(16.7)$ \\
\hline $\mathbf{8}$ & 5 & $5(100)$ & $4(80.0)$ & $2(40.0)$ \\
\hline $\mathbf{9}$ & 8 & $0(0)$ & $0(0)$ & $0(0)$ \\
\hline $\mathbf{1 0}$ & 4 & $4(100)$ & $3(75.0)$ & $3(75.0)$ \\
\hline $\mathbf{1 1}$ & 16 & $4(25.0)$ & $3(18.8)$ & $3(18.8)$ \\
\hline $\mathbf{1 2}$ & 10 & $6(60.0)$ & $5(50.0)$ & $6(60.0)$ \\
\hline $\mathbf{1 3}$ & 18 & $13(72.2)$ & $6(33.3)$ & $13(72.2)$ \\
\hline $\mathbf{1 4}$ & 5 & $2(40.0)$ & $2(40.0)$ & $0(0)$ \\
\hline $\mathbf{1 5}$ & 5 & $4(80.0)$ & $4(80.0)$ & $4(80.0)$ \\
\hline $\mathbf{1 6}$ & 9 & $4(44.4)$ & $4(44.4)$ & $4(44.4)$ \\
\hline $\mathbf{1 7}$ & 5 & $1(20.0)$ & $0(0)$ & $1(20.0)$ \\
\hline Average & & $50.7 \%$ & $38.2 \%$ & $35.7 \%$ \\
\hline & & & & \\
\hline
\end{tabular}

On average, data were discussed and interpreted for about half of the students $(51 \%)$. This means that for the other half of the students, no data were used across the meetings. The observations indicated that this share of students was generally not even the subject of discussion because teachers did not formulate a clear problem or situation sketch. In other words, their learning processes were not discussed at the team meetings. Diagnosing causes underlying the data happened for about $38 \%$ of the pupils who were discussed, whereas 
concrete actions were formulated for about $36 \%$ of the pupils. This implies that data discussion and interpretation do not end in concrete guidance actions for all students.

It is necessary to emphasize that there are great differences across the team meetings in the extent to which data are used for student guidance. As Table 2 shows, in one team (Team 9)no data discussion took place. In every other team, data discussions were initiated. However, the extent of pupils who were the subject of data discussion varied a lot across teams. The two classes in which the teams discussed data for all the students were small (4 and 5 students). Class size is not obviously related to the extent of data discussion; for some larger class groups, a high number of data discussions were initiated (e.g., Team 13). On the other hand, the extent of data use for some smaller pupil groups was rather limited (e.g., Team 6 and Team 17).

Table 3

Sequential interruptions in data use

\begin{tabular}{|l|c|c|}
\hline & N & Percentage \\
\hline Completed inquiry circles & 38 & 56.7 \\
\hline Only discussion and interpretation & 8 & 11.9 \\
\hline Discussion, interpretation, and diagnosis & 10 & 14.9 \\
\hline No diagnosis & 11 & 16.4 \\
\hline Total processes & $\mathbf{6 7}$ & \\
\hline
\end{tabular}

The observations indicated that teachers in the team meetings do generally not use data in a systematic way. Table 3 provides an overview of the interruptions in the data use sequence of the 67 student guidance processes in which data use was initiated (i.e., in which data were discussed). In 38 of those processes $(57 \%)$, the data use sequence was completed. The 29 other data use processes $(43 \%)$ were incomplete or showed imperfections from a theoretical perspective. Incomplete data use sequences stopped after data discussion $(\mathrm{N}=8)$ or after data diagnosis $(\mathrm{N}=10)$. This implies that student data (e.g., subject scores) were only discussed (in 8 cases) or that teachers talked about potential causes (in 10 cases) but that no discussion on appropriate actions took place. Next to this share of incomplete data use processes, there was a reasonable share of data use sequences in which the diagnosing phase was skipped (in 11 cases). In these processes, teachers formulated actions without deliberation on potential causes for the student's problem. Whereas the incomplete data use sequences came to the front in different teams, the data show that a large number of processes that skipped the diagnosing phase occurred within one team. 


\section{The Depth of Inquiry in Data Use}

\section{The diagnosing phase}

The analysis regarding the depth of inquiry in the team meetings focused on the concept of attribution. Figure 1 presents a visualization of the number of coded fragments in the diagnosing phases. The figure makes clear that the vast number of discussed causes among the teachers were external and controllable. All causes were externally attributed. None of the discussed causes related to the teachers or their teaching. Teachers all pointed at student "problems" as causes for, for example, underachievement.

Within these external causes, the majority of the causes that were raised were controllable by teachers. Learning problems within certain subjects (e.g., math problems) and problematic learning attitudes were mentioned the most (in 52 of the 58 coded fragments). But next to that, emotional problems (in 5 coded fragments) and language issues (in 1 coded fragment) came to the surface. There were no clear differences in diagnostic processes based on the presented topic.

Some of the external causes that teachers perceived were uncontrollable. Most of the time these causes related to student characteristics or student learning environments. Student learning disorders (e.g., autism or ADHD) and their medical hindrances (e.g., chronic headaches) were the most important causes mentioned in this category (in 5 and 4 coded fragments respectively). The problematic home environments of students also came to the surface (in 2 coded fragments). Generally, the externally attributed causes that were uncontrollable by teachers were less present in the observational data.

Figure 1

Causal attribution in data use
External attribution

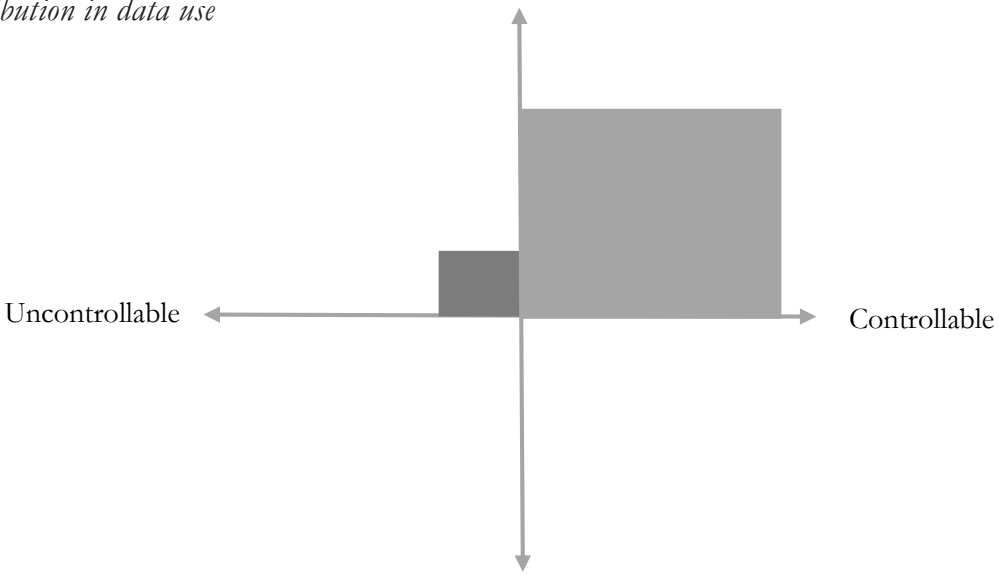

Internal attribution 


\section{The formulated actions}

The formulated actions were distributed into four categories, based on the different actions that were distinguished by Coburn and Turner (2011): adapting instruction, materials, grouping pupils, and other dimensions of the classroom and school practice.

First, the most common actions that were formulated across the team meetings related to providing students with supplemental materials. This strategy came to the front in 40 of the 61 coded fragments on formulating actions. Teachers mainly suggested remedial assignments (in 15 of the coded fragments) and additional assignments during holidays (in 15 of the coded fragments). But next to that, additional exercises and additional tests were formulated as actions during the team meetings (in 8 and 2 coded fragments respectively).

Besides providing students with materials, teachers suggested some other actions in the team meetings. This other category appeared to be the second biggest in the data set (11 of 61 coded fragments). Mainly when it came to problematic student behaviors, alternative actions were suggested. Examples included follow-up meetings with students and parents (in 5 and 3 coded fragments respectively); in some cases there was agreement on behavior contracts with students (i.e., in 3 coded fragments).

Adapting instruction came to the front in the observational data but was not a common action after the data use processes. Of the coded fragments, 10 related to this category. For some students, teachers agreed upon adapted guidance in class (in 6 of the coded fragments). In two cases, the team decided on an adapted school trajectory (e.g., a combination of school and work); in two other cases, the teachers agreed to provide them with additional lessons.

The analysis of the observation notes made clear that subgrouping pupils was not a strategy in the different team meetings. This strategy was not suggested in any of the 17 meetings.

\section{Discussion}

What education can bring about for students depends on how their learning processes are guided and therefore on the educational decisions teachers make. Systematic data use offers the potential for teachers to improve student guidance. In this regard, it is essential that data use follows a sequence of discussion and interpretation, diagnosis, and action. It is also vital that teachers take a self-reflective stance in the examination of causes and formulation of improvement actions (Schildkamp et al., 2016). This study investigated teacher use of data at formal student guidance meetings. The aim of this in-depth 
qualitative study was twofold. The observations of 17 formal student guidance meetings in Flanders provided insight into the extent to which the data use circle of inquiry was followed and the depth of inquiry in these data use processes.

A first finding was that of all 149 students that were the subject of discussion at the team meetings, only about half of them (51\%) were discussed at the team meetings in a way that was supported by data. The main reason for teachers to start discussing and interpreting data was the consideration that there was a problem with student functioning. Concerning the other half of the students, who did not show clear problems, there was almost no discussion. Teachers only discussed students with obvious learning problems; they did not discuss, for example, talented students who needed more challenges or deepening in the course materials. Given that the observed team meetings are the only formal occasions for the teams to make arrangements on student learning trajectories, this finding implies that for about half of the students, data-based reflection on student guidance among teachers was missing. A high responsibility remains with individual teachers to properly detect and follow up needs for gifted students. This may also have consequences for the advisory function of the team toward students for their study progress. The question arises of whether the team meetings can result in clear and data-informed picture of all student capacities.

Two elements are important to highlight to explain these findings. The fact that teachers all teach different subjects may imply that they consider their teaching task as an individual practice and responsibility. In this perception, teachers may not raise issues they consider as specific for their teaching. As a result, only problems that exceed individual teaching practices come to the front at formal team meetings. Such a lack of connectedness for teaching and learning in interdisciplinary teams is not uncommon in educational research, and in data use research in particular (Van Gasse et al., 2017). The downfall, however, can be that teachers do not have the full picture of student functioning because teachers do not share information when none of the teachers have the feeling that there are serious problems. As such, some issues in regular or gifted student guidance might be overlooked in the early stages and no optimal data-based guidance is provided.

The second explanation can be that teachers often only initiate data use processes when problems are perceived (i.e., problem-based data use) (Ansyari et al., 2020). Such data use following intuition is effective in installing data use practices when teachers are not familiar with it. Working on problems that teachers recognize and acknowledge can be a stimulus for using data in schools (Schildkamp et al., 2016). However, when data use only follows the "intuitive" problems of teachers, student guidance processes still strongly depend on teachers' pre-existing assumptions. Again, students will only be 
"guided" when teachers (or parents, student counsellors, or students themselves) perceive problems, not when students do not differentiate in behavior or achievement from the modal student. Therefore, relying only on problem-based data use cannot avoid and may even facilitate some of the cognitive biases (e.g., attention bias) that data use is expected to counter. There is also a risk that teachers' advice for student trajectories that follows later on is based on intuition rather than on knowledge that is built within the team meetings.

A second finding in this study is that slightly more than half (i.e., $57 \%$ ) of the observed student guidance discussions in which data were discussed and interpreted followed the subsequent phases of the data use circle of inquiry. Our analysis showed a considerable number of data use processes that stopped after the discussion and interpretation or diagnosing phase. Further, a reasonable share of discussions were observed in which the diagnosing phase was skipped. In other words, in these student guidance processes teachers did not search for possible causes before coming up with improvement actions. The need for diagnosis lies in challenging existing (intuitive) assumptions. Although some experienced teachers may choose appropriate improvement actions based on their expertise, skipping this phase results in a higher risk for cognitive biases in decision making (e.g., confirmation bias or attention bias). Bearing in mind that data was used in only half of the student guidance processes, the data use cycle was completed in about a quarter of these processes.

Interruptions in the data use cycle and skipping phases have also been observed in other studies in data use (e.g., Marsh \& Farrell, 2015). Because teachers in this study were not bound to the phases by means of an intervention design or a coach, it is likely that the teams in the study were not aware of what effective data use processes look like. In Flanders, data use is not a common activity, so the data use cycle is not widely known (Van Gasse et al., 2017). The first step in being successful in data use is knowing how the process should look. Only then can all the necessary other competencies that are needed for effective data use (i.e., data literacy) be used.

The last general finding in this study concerns teachers' causal attribution in the data use processes studied. This study showed that teachers only formulated external causes. The cause of student (learning) problems was always assigned to the students themselves (for example, their learning attitude or their subject-specific learning problems). Interactions between teacher practices and student functioning were never raised. As a result, actions that were formulated generally related to the level of the student (for example "providing additional exercises") and only exceptionally to the level of teacher activities. As such, the responsibility for improvement lay mainly with the students. In a limited number of guidance processes, 
actions were formulated at the level of the learning trajectory or the instructional strategy that was used. The depth of inquiry as conceptualized in this study was rather limited.

The idea that teachers tended not to question their own functioning at the team meetings is not quite surprising. Generally speaking, people tend to attribute successes to their personality and failures to contextual factors (Weiner, 2010). In the field of data use research, the depth of inquiry in data use processes was sometimes questionable because teachers predominantly identified external causes (Schildkamp et al., 2016). This can be due to the fact that processes that need to be questioned are directly related to teacher functioning. This is a sensitive matter and teachers may not like to discuss these issues with all of the colleagues of the formal team. Prior research has shown that the colleagues whom teachers consult for data use are people with whom they maintain friendship-relationships (Van Gasse et al., 2020).

The qualitative research design with observations enabled us to study the data use processes in depth. As such, we learned that only a limited number of student guidance processes are underpinned with data use processes as described in the literature. However, our study sample contained 17 formal teams from two schools. Therefore, the (data use) culture in these schools may have affected our data collection and results as the variation between teams within the schools may be smaller than between schools (i.e., multilevel problem). The research design did not account for this fact.

Another limitation of this study is that it digs deep into the processes of data use but did not shed light on the bigger picture of these processes. This study involves cross-sectional data. This implies that we did not gain insights into the whole guidance process of students during the school year. Additionally, it remains unclear what these data use processes at formal team meetings provide for teachers and students. Maybe despite the superficial processes, the fact that teachers hear stories of each other's practices and discuss improvement actions for students results in later reflections on strategies to cope with certain problems of pupils. As such, some aspects of data literacy (e.g., pedagogical knowledge) may be developed during the meetings. Another effect of data use at student guidance meetings is what it delivers for students. For example, were the actions that were formulated effective for students or how did they perceive them? Fully understanding data use processes requires some insights into the effects as well. Although these insights are often lacking in data use research, they are indispensable to assess and evaluate how effective data use processes should look (Ansyari et al., 2020). 


\section{Conclusion}

This study has generated some important implications for future research and practice. The results show that achieving complete and in-depth cycles in data use is not an easy endeavor. Therefore, it is crucial to gain insight into how effective data use can be stimulated. A lot of efforts have been made to support data use activities in schools through intervention research. However, it is clear that whereas core teams may get engaged in data use, this engagement does not always flow through the entire school (Hubers et al., 2017). As we know that the relation between formal and informal networks may play an important role here (Van Gasse, 2019), it is crucial to gain insight into how data use can be facilitated apart from intervention settings. In line with what we stated earlier, effect measures should play a role. Assessing and evaluating "what works" in data use cannot take place without considering the long-term and short-term effects. Additionally, more information is needed to explain the current findings. How can decision making on pupils guarantee an appropriate balance between intuitive expertise and data-based decision making? And why does the current balance favor intuition over evidence?

Second, to ensure that teacher teams succeed in completing data use cycles, more insight is needed in how data literacy as a cluster of competencies can be influenced. Data literacy starts with knowing how to implement the data use cycle and being familiar with its challenges and pitfalls. Analytical and data interpretation skills are only a part of the puzzle (Gummer \& Mandinach, 2015). Therefore, more insight is needed in how all these particular competencies can be learned by teachers. This can start with research into how data literacy can be measured; such measurements could lead to effect studies on data literacy interventions, such as collaborative inquiry, learning by case studies, etc.

This study is among the first to use systematic observations to expose how teachers use data at formal student guidance meetings. It reveals that the implementation of the data use cycle and the depth of inquiry during this implementation are questionable. Therefore, for Flemish policymakers and practitioners it is essential to raise awareness on the stepwise self-questioning process that data use should be. As efforts are currently being made in Flanders to increase teacher (statistical) data literacy skills, it is crucial to emphasize the importance of approaching data literacy as a broader cluster of competences. Competences to adequately use data for improvement processes start with being aware of the theory of action behind it. Other essential competences (e.g., goal setting, self-questioning, and reflection skills) are also needed to complete the process with a reasonable depth of inquiry. Only by responding to this whole cluster of competences will teachers be able to optimize pupil guidance processes on the basis of data. 


\section{References}

Ansyari, M. F., Groot, W., \& De Witte, K. (2020). Tracking the process of data use professional development interventions for instructional improvement: A systematic literature review. Educational Research Review, 31, 1-18. https://doi.org/10.1016/j.edurev.2020.100362

Baten, E., Vansteenkiste, M., De Muynck, G.-J., De Poortere, E., \& Desoete, A. (2020). How can the blow of math difficulty on elementary school children's motivational, cognitive, and affective experiences be dampened? The critical role of autonomy-supportive instructions. Journal of Educational Psychology, 112(8), 1490 -1505. https://doi.org/10.1037/edu0000444

Bertrand, M., \& Marsh, J. A. (2015). Teachers' sensemaking of data and implications for equity. American Educational Research Journal, 52(5), 861-893. https://doi.org/10.3102/0002831215599251

Campbell, C., \& Levin, B. (2008). Using data to support educational improvement. Educational Assessment, Evaluation and Accountability, 21(1), 47-65. https://doi.org/10.1007/s11092-0089063-x

Carlson, D., Borman, G., \& Robinson, M. (2011). A multistate district-level cluster randomized trial of the impact of data-driven reform on reading and mathematics achievement. Education Evaluation and Policy Analysis, 33(3), 378-398. https://doi.org/10.3102/0162373711412765

Ciampa, K., \& Gallagher, T. L. (2016). Teacher collaborative inquiry in the context of literacy education: Examining the effects on teacher self-efficacy, instructional and assessment practices. Teachers and Teaching, 22(7), 858-878. https://doi.org/10.1080/13540602.2016.1 185821

Coburn, C. E., \& Turner, E. O. (2011). Research on data use: A framework and analysis. Measurement: Interdisciplinary Research \& Perspective, 9(4), 173-206. https://doi.org/10.1080/ 15366367.2011.626729

Datnow, A., \& Hubbard, L. (2015). Teachers' use of data to inform instruction: Lessons from the past and prospects for the future. Teachers College Record, 117(4), 1-26.

Datnow, A., \& Hubbard, L. (2016). Teacher capacity for and beliefs about data-driven decision making: A literature review of international research. Journal of Educational Change, 17(1), 7-28. https://doi.org/10.1007/s10833-015-9264-2

De Volder, I. (2012). Externe schoolevaluaties in Europa. Garant.

Ebbeler, J., Poortman, C. L., Schildkamp, K., \& Pieters, J. M. (2017). The effects of a data use intervention on educators' satisfaction and data literacy. Educational Assessment, Evaluation and Accountability, 29(1), 83-105. https://doi.org/10.1007/s11092-016-9251-z

Ehren, M. C. M., \& Swanborn, M. S. L. (2012). Strategic data use of schools in accountability systems. School Effectiveness and School Improvement, 23(2), 257-280. https://doi.org/10.1080/ 09243453.2011.652127

Gelderblom, G., Schildkamp, K., Pieters, J., \& Ehren, M. (2016). Data-based decision making for instructional improvement in primary education. International Journal of Educational Research, 80,1-14. https://doi.org/10.1016/j.ijer.2016.07.004

Gummer, E. S., \& Mandinach, E. B. (2015). Building a conceptual framework for data literacy. Teachers College Record, 117(4), 1-22.

Hubers, M. D., Moolenaar, N. M., Schildkamp, K., Daly, A., Handelzalts, A., \& Pieters, J. M. (2017). Share and succeed: The development of knowledge sharing and brokerage in data teams' network structures. Research Papers in Education, 1-23. https://doi.org/10.1080/026 71522.2017 .1286682 
Hubers, M. D., Poortman, C. L., Schildkamp, K., Pieters, J. M., \& Handelzalts, A. (2016). Opening the black box: Knowledge creation in data teams. Journal of Professional Capital and Community, 1(1), 41-68. https://doi.org/10.1108/JPCC-07-2015-0003

Marsh, J. A. (2012). Interventions promoting educators' use of data: Research insights and gaps. Teachers' College Record, 114, 1-48.

Marsh, J. A., Bertrand, M., \& Huguet, A. (2015). Using data to alter instructional practice: The mediating role of coaches and professional learning communities. Teachers College Record, 117(4), 1-40.

Marsh, J. A., \& Farrell, C. C. (2015). How leaders can support teachers with data-driven decision making: A framework for understanding capacity building. Educational Management Administration \& Leadership, 43(2), 269-289. https://doi.org/10.1177/1741143214537229

Schildkamp, K., Poortman, C. L., \& Handelzalts, A. (2016). Data teams for school improvement. School Effectiveness and School Improvement, 27(2), 228-254. https://doi.org/10.1080/0924345 3.2015.1056192

Van Gasse, R. (2019). The effect of formal team meetings on teachers' informal data use interactions. Frontline Learning Research, 7(2), 40-56. https://doi.org/10.14786/flr.v7i2.443

Van Gasse, R., Vanlommel, K., Vanhoof, J., \& Van Petegem, P. (2016). Teacher collaboration on the use of pupil learning outcome data: A rich environment for professional learning? Teaching and Teacher Education, 60, 387-397. https://doi.org/10.1016/j.tate.2016.07.004

Van Gasse, R., Vanlommel, K., Vanhoof, J., \& Van Petegem, P. (2017). Unravelling data use in teacher teams: How network patterns and interactive learning activities change across different data use phases. Teaching and Teacher Education, 67, 550-560. https://doi.org/10.1016/j. tate.2017.08.002

Van Gasse, R., Vanlommel, K., Vanhoof, J., \& Van Petegem, P. (2020). Teacher interactions in taking action upon pupil learning outcome data: A matter of attitude and self-efficacy? Teaching and Teacher Education, 89, 1-9. https://doi.org/10.1016/j.tate.2019.102989

Vangrieken, K., Dochy, F., Raes, E., \& Kyndt, E. (2013). Beyond individualism and isolation in schools: What types of teacher teams are there in schools? Or can we merely speak about groups? Frontline Learning Research, 1(2), 86-98. https://doi.org/10.14786/flr.v1i2.23

Verhaeghe, G., Vanhoof, J., Valcke, M., \& Van Petegem, P. (2010). Using school performance feedback: Perceptions of primary school principals. School Effectiveness and School Improvement, 21(2), 167-188. https://doi.org/10.1080/09243450903396005

Wayman J., Spikes D., Volonnino M. (2013) Implementation of a Data Initiative in the NCLB Era. In: K. Schildkamp, M. Lai, \& L. Earl (Eds.), Data-based Decision Making in Education: Challenges and Opportunities (pp. 135-153). Springer. https://doi.org/10.1007/978-94-007-4816-3_8

Weiner, B. (2010). The development of an attribution-based theory of motivation: A history of ideas. Educational Psychologist, 45(1), 28-36. https://doi.org/10.1080/00461520903433596

\section{Corresponding authors}

Roos Van Gasse

Department of Training and Educational Sciences, University of Antwerp, Belgium

E-mail: roos.vangasse@uantwerpen.be

Martine Mol

Antwerp School of Education, University of Antwerp, Belgium

E-mail:martine.mol@uantwerpen.be 
